\title{
Using Microlearning and Social Learning to Improve Teachers' Instructional Design Skills: A Mixed Methods Study of Technology Integration in Teacher Professional Development
}

\author{
George Hanshaw (corresponding author) \\ Office of Innovative Teaching and Technology, Azusa Pacific University (APU) \\ 680 Alosta, Azusa, CA 91702-7000, USA \\ Email: ghanshaw@apu.edu
}

Tel: 1-(626)-387-5886

Janet Hanson

Department of Educational Leadership, Azusa Pacific University (APU)

PO Box 7000, Rm 137, Azusa, CA 91702-7000, USA

Email: jhason@apu.edu

Tel: 1-(626)-815-5375

Received: September 28, 2017 Accepted: February 1, 2019 Published: February 25, 2019 doi:10.5296/ijld.v9i1.13713ＵRL: https://doi.org/10.5296/ijld.v9i1.13713

\begin{abstract}
The purpose of this mixed-method study was to test the usefulness of a new technology-based instructional design, using microlearning and social learning, to improve employee skills on the job. Researchers collected data from professionals responsible for instructional design at
\end{abstract}


their workplace $(N=51)$. Participants engaged in a fully on-line training at a time convenient to them over a two-week period. A learning management system supported the content delivery. A social learning component included video demonstrations of the content and participants asynchronously sharing their learning with other participants. Researchers performed follow-up interviews $(N=10)$ to develop a deeper understanding of the participants' perceptions and to validate self-reports collected in a Likert-style quantitative survey. Participants created work samples used as evidence of their learning from the training. Three themes emerged from the qualitative analyses including, participants wanted training that provided skills useful immediately on the job, sought to expand their perspectives by learning from others, and to expand their skills in their craft beyond those of other designers. Participants' reported that opportunities to share their learning with others made the learning "more personal" and provided a "bigger picture," or broader perspective. Participants' reported the instructional design increased their motivation to engage the content and that their skills improved. Positive reports of the effectiveness of the microlearning component were not consistent, however, with the statistical results. There was a significant negative correlation between microlearning and the social learning component and the dependent variable of the study, participants' perceptions of the effectiveness of the instructional design.

Keywords: instructional design, microlearning, social learning, professional development, information and communication technology, scenario-based learning

\section{Introduction}

Instructional designers need professional development to understand the complex balance of scope, aim, and goals of integrating online and mobile technologies into the historically social process of teaching and learning (Kovalchuck \& Vorotnykova, 2017). There is no specific peer-reviewed research at this time reporting results of the effectiveness of ID in a professional development setting that used a combination of ML and SL delivered on mobile devices. This study adds to the literature in this area.

The use of information technologies (IT) in instructional design (ID) is increasing rapidly. U.S. industry leaders initially introduced IT into instructional design in the K-12 education system, stating its use would bring improvements in student learning. State leaders and private groups began recommending technology implementations for such activities as standardized testing, developing 21st Century skills in students, and later into institutions of higher education. Historically, instructional designers integrated IT into instructional practices as a tool to solve teaching problems. However, IT is not entirely a technical tool, or just a field of engineering. IT can become an end in itself due to its complexity and the ever-expanding diversity of IT tools in "app stores," online, the marketplace, and in our societal institutions. IT directly influences human thought and behavior. People have come to identify with IT and even to "define themselves by it (Gedik, 2017, p. 86). Ethical considerations were not included in the definition of IT developed by the Association of Educational Communications and Technology (AECT) until 2007. Concerned researchers warned the use of IT is "diverging from instructional design (ID), and not considering the needs and real problems of the ...context. [S]tudies have confirmed this divergence, in that very few studies have investigated ID” (p. 93). 
Well-developed ID must reflect the needs of the learner. Teachers, as instructional designers, need a strong foundation and understanding in the theory, aims, scope, and purposes of IT in order to integrate its elements appropriately into the instructional design of their trainings/courses. For example, each school, business, country, and culture has a unique context. Responsible use of IT includes a focus on meeting the needs of the individuals and groups it serves, being responsive to their input and to the culture and context of each environment.

Adults benefit from pedagogical practices that integrate technology in instructional design, referred to as "a bridge between science and practice" (Gedik, 2017, p. 84). Developing the full potential of the IT use in ID requires the support of multiple learning theories. As Taylor and Hamdy (2013) explained, "None of the individual theories fully explain [in isolation] what is happening when an aspiring ... professional is engaged in learning" (p. e1561). The current study employed the use of a new instructional design (ID) that incorporated a scenario-based learning (SBL) approach and an online learning management system (LMS) to deliver content to mobile devices, available to the participants anytime, anywhere; at times convenient to them. ML in the workplace is a highly focused delivery of learning materials in small chunks through online delivery, including mobile devices and multiple other formats. ML reduces the time and cost of professional development compared to face-to-face brick-and-mortar designs, personalizes the learning content, and promotes learner self-direction.

Social learning (SL) is a key component of adult learning. Chen and Bryer (2012) reported that only five percent of adult learning occurs through formal learning. Social learning results through developing informal relationships and enhanced participation. When embedded into PD, SL takes into account a learner's choice to engage content and to share information through channels not usually embedded in formal structures. For example, individuals share information that answers questions when needed in the workplace, at home, or anywhere in life using social media, asynchronous video messaging, text messaging with peers, FaceTime, and or Twitter (Lindsay, 2016).

\subsection{Purpose of the Study}

This study tests the usefulness of a new ID to increase participants' motivation to engage the learning content and to become self-directed reflective learners, using microlearning and social learning components. In a prior study performed by the authors, professionals shared they were ready and wanted to engage learning using ML as well as to become their own content creators (Hanshaw \& Hanson, 2018). This research expands on the results of the previous study by integrating a SL component into the instructional design tested and collecting work sample artifacts to verify participants self-reports of their perceptions of the effectiveness of the training modules. The ID of the study sought to enhance learner motivation by providing opportunities for their input. Participants created interactive videos to share their learning experiences asynchronously with peers. The use of an interactive platform developed a sense of social connection by simulating peer-to-peer e-mentoring through asynchronous discussions (Kovalchuck \& Vorotnykova, 2017). Flipgrid, an online learning tool, provided the format for the asynchronous social-interaction platform in this study. Participants chose their own 
technology device to perform the tasks; e.g. laptops, tablets, or cell phones. The majority of participants used a mobile device. The LMS also delivered and collected participants' responses to a quantitative survey tool.

\subsection{Research Question}

The mixed-methods research design of this study sought to collect reliable data to answer the following overarching questions:

How do participants perceive and experience the usefulness of a combination of micro-learning and social learning to meet the learners' needs and produce an increase in their professional instructional design skills?

Sub-question 1 - How do the participants perceive and experience the social learning component used in the instructional design of this study to motivate participants' engagement in learning?

Sub-question 2 - How do the participants perceive their experience with the micro learning instructional design components used in this study?

Sub-question 3 - Is the mobile technology-based ML and SL instructional design, implemented in this study, useful to affect a change in the participants' work-related behaviors as demonstrated by the participants' self-reports and the quality of participants' work samples (e.g. writing learning objectives)?

\subsection{Hypotheses}

The following hypotheses were tested using quantitative analyses in this study:

Hypothesis $_{01}$ - There is no relationship between the participants' perceptions that using a combination of ML and SL is an effective way to increase their design skills (Item 7) and individual mean scores calculated from the items on the Likert-style study survey.

Alternative Hypothesis ${ }_{1}$ - There is a relationship between the participants' perceptions that using a combination of ML and SL is an effective way to increase their design skills (Item 7) and individual mean scores calculated from the items on the Likert-style study survey.

Hypothesis $_{02}$ - There is no relationship between participants' self-reports of their belief ML and SL improved their skills in instructional design and their work sample quality.

Alternative Hypothesis ${ }_{2}$ - There is a relationship between participants' self-reports of their belief ML and SL improved their skills in instructional design and their work sample quality.

\subsection{Researcher Positionality}

The first author holds a doctorate degree in Psychology and works as an instructional designer to support faculty course development at a mid-sized private university in a large southwestern state of the U.S. The second author holds a terminal degree in educational leadership and teaches masters' level coursework to candidates seeking credentials as K-12 public school administrators. Both have extensive experience in developing instructional design and with 
technology integration in K-12 and higher education.

The researchers declare a positive bias that using ML and SL strategies would improve workplace skills/behaviors and improve participants' engagement and motivation to learn. Therefore, the research design included rigorous processes recommended by Yin (2014) and Maxwell (2013) to protect against negative influences from researcher bias. The researchers designed the self-developed survey questions using a Likert-type rating scale. The interview protocol used semi-structured open-ended questioning, so as not to imply there were correct answers to the questions asked by the interviewer. The researchers sought the respondents' true point of view. The researchers triangulated the study findings with the literature to reflect prior studies' findings and to support the validity of the conclusions drawn from the data.

\subsection{Definition of Terms}

Following is a list of definitions of terms used in this paper.

Asynchronous learning: a learner-centered approach to learning that does not require specified times or groups of learners to be present together. Learners are able to engage with content where and when they choose.

Synchronous learning: occurs during a specified time and place with a specific group of people. Learners can accomplish synchronous learning online. However, synchronous learning is different from asynchronous learning because of the synchronized time and location requirement.

Instructional technologies (IT): include the use of information and communication technologies into instruction such as SMARTboards, computers, audiovisual materials, internet technologies and applications, and used according to the characteristics and needs of the subject, learners, instructors, and context (Sarac, 2018, p. 189).

Terminal objective: states what the learner will be able to do (perform) once the training/learning is complete. The terminal objective contains the performance (what the learner will do), condition (circumstance the learner will be able to perform the task under), and criteria (how well the learner must perform the function) (Mager, 2004).

Enabling objective: learning objectives that contain the same component as the terminal objective. Enabling objectives act as a performance path for the learner to meet the requirements of the terminal objective.

Formal learning: “... is learning supported by an educational or training institution, structured [and] controlled by a teacher or a guide, resulting in a certificate" (Kyprianou \& Nikiforou, 2016, p. 249).

Informal learning: "...is not supported by an educational, or training, institution. It is controlled by the learner" (Kyprianou \& Nikiforou, 2016, p. 249).

Heutagogy is self-directed learning. Cochrane and Narayan (2013) argued, "Heutagogy does not imply an abdication of the responsibility of a teacher, but involves a reconceptualization of the roles of the teacher and learner" (p. 2). This 'redefinition' of the role of the learner is crucial 
to the success of a ML initiative.

Instructional designers: are instructional trainers and training instructors, who have all performed instructional design.

Leader: a decision maker within an organization who has direct reports. This may be a manager or other position of formal authority.

Learning management system: (LMS) the online resource that contains all the assignments, video tools and participants' responses used in instructional application. Schoology was the LMS used in this study (Schoology, 2018).

Microlearning $(M L)$ : is a "catch phrase" for a variety of new technologies and web applications used for learning using "digital micro content." ML uses small learning units and short-term learning activities. People engage in ML when "seeking information to build new knowledge in networked digital media environments such as email, mobile phones, Google, and Web 2.0" (Jaokar, 2007, p. 44). The learning objects for this study were interactive videos, less than four minutes in length, with social learning activities attached to the end of the ML object.

Social learning $(S L)$ : is a form of informal learning that occurs through relationship and participation. When embedded into PD, SL takes into account a learner's choice to engage content and then share information through channels not usually embedded in formal structures.

Millearnials: a neologism term used to describe workers of all ages, who wish to access media-rich and highly relevant learning content through their mobile devices (Stokely, 2015).

Performance-based learning objects: either terminal or enabling learning objectives that contain the three components: performance, condition, and criteria (Mager, 2004). Performance learning objectives focus on specific performance and measure the learner's ability to perform that function.

Continuing professional development (PD): “... a commitment by members to continually update their skills and knowledge in order to remain professionally competent and achieve their true potential" (CAE, n.d. in Kyprianou \& Nikiforou, 2016, p. 249).

Scenario-based learning approach (SBL): an instructional design that includes three basic attributes: providing the learner with a real world situation for learning content, assessment tasks for learners to demonstrate their learning, and ability of the instructor to determine a measure for the participant's growth toward meeting the predetermined outcomes of the instruction (Karunanayaka et al., 2018, p. 181).

Social media: "[T] internet technologies." Examples of social media applications include Facebook and Twitter for social networking (Sarac, 2018, p. 190).

A review of the literature follows including the use of instructional design for changing workplace behaviors, social learning, microlearning, andragogy, institutional readiness, mobile technology, and scenario-based learning design. 


\section{Review of the Literature}

\subsection{Instructional Design for Improvement in Workplace Behaviors}

There is no shortcut to improving workplace performance. A review of the literature revealed that over 50 hours of training is required to create a change in an individual's practices. However, the use of online tools can aid the process (Kyprianou \& Nikiforou, 2016). Microlearning can deliver training at a time convenient to the learner. Combining ML with SL takes on a more heutagogical approach by allowing for learner self-direction. The smaller-chunk approach to content delivery is effective in improving motivation for adult learners in particular by allowing learning to proceed over time in spite of demanding or distracting schedules. Studies of medical students in China (Wen \& Zhang 2015), government workers in Austria (Bruck, Motiwalla, \& Foerster, 2012), and undergraduates in Germany (Giurgiu, 2017) have shown improved motivation and/or course completion rates as effects of ML interventions. Billings and Kasmer (2015) evaluated a ML-facilitated change in behavior through professional development of math teachers. They reported, "All the teachers demonstrated evidence of change in their professional learning" (p. 178). It is important to note, that the use of ML is more successful in developing certain types of behaviors than others. Changes in workplace behaviors from the use of ML are often incremental and require iterative processes to attain the learning. This compared favorably with Gassler, Hug and Glahn's (2014) explanation that a learning activity must occur on a regular basis in order to be effective. Matzen and Edmunds (2007) found that the use of technology for professional development changed the instructional behaviors of teachers through their use of computers. Kyprianou and Nikiforou (2016) explained the benefits of technology in their informal approach to CPD as facilitating coordination, organization, motivation, communication, collaboration, problem solving, and reflection on the work (p. 252).

\subsection{Instructional Technology in Instructional Design}

\subsubsection{Social Learning}

The growth of social media for educational purposes has not grown proportionally with the use of social media for personal reasons. Today, integrating mobile e-learning formats with social media provides unprecedented opportunities for self-reflection and learning through an iterative process of "micro" experiences. Dewey (1910) suggested that the social environment and social interactions of teaching and learning are of paramount importance to the quality of one's learning. SL affects the quality of an individual's learning; a dimension not necessarily captured in traditional measures of grades and standardized test scores. The use of SL can help remove long-standing barriers between formal and informal learning. Breaching this barrier shows a potential to leverage the informal workspace where the vast majority of learning occurs. Hattie (1999 and 2012), in a massive, ongoing meta-study of effects on teaching and learning, consistently found social aspects of teaching and learning at the top of the list of the most impactful factors and interventions. Research findings support the use of SL strategies in ID. For example, Waack (2015) reported collective teacher efficacy was the number one factor contributing to student learning. Siadaty, Gašević, \& Hatala's (2016) case study reported workplace training was most impactful when it promoted social awareness, used ML, and 
provided technological scaffolding interventions.

\subsubsection{Microlearning}

Dewey (1910) provided a philosophical framework for learning in smaller chunks. He wrote, "Concentration does not mean fixity, nor a cramped arrest or paralysis of the flow of suggestion. It means variety and change of ideas combined into a single steady trend moving toward a unified conclusion" (p. 10). He further expounded on the mechanism for improving learning through an iterative process of reflection. Ensuing decades of study and implementation of reflective practices in teaching and learning validated this model (Dewey, 1933). There is efficacy in the use of ML strategies along with SL for interactions and engagement in order to increase teacher ID skills. The use of mobile technology to deliver chunks of content, SL tools providing asynchronous and synchronous opportunities for learners to interact with each other and with the learning, is a critical component to the success of any ML initiative.

The use of mobile technology to deliver and interact with adults' learning opportunities is a critical component to the success of ML interventions. Matzen and Edmunds (2007) found that the use of technology for PD changed the instructional behaviors of teachers. Their use of computers and effective leveraging of ML strategies with SL improved participant interactions and engagement, resulting in increased instructional design skills. In another study, surgeons in Connecticut performed significantly better on an in-service examination when they participated in a gamified microblogging project on Twitter (Lamb et al., 2017). Students of all ages are spending much of their time in online informal social media spaces. Microlearning, integrated into a social media environment, has the potential to harness a rich SL environment and advance formal learning goals; accessing the ninety-five percent of learning that occurs through informal social exchanges.

\subsection{Andragogy}

Fundamental principles of andragogy suggest that education for adults should not resemble elementary education or treat adult learners as if they are children, though much corporate training still does (Knowles, 1984). Using knowledge of the learner and the learning context strongly supports using ML and SL over traditional curricula and PD delivery systems. The learning needs of adults (andragogy) are front and center in the race for economic success.

\subsection{Institutional Readiness}

Rapid technological change mandates a shift to updated processes for delivering instruction and lifelong learning. Even though research provides evidence that learners are ready for ML in their PD, administrators have not integrated ML and SL into the ID for continuous PD on a broad scale. For example, Musa (2014) found that ML approaches had not being widely implemented in a teacher training program in Turkey, despite the students' interest in, and successful experiences with, the approach. School and business leaders need training and understanding on how to support and sustain successful IT integration into ID. Hanshaw and Hanson (2018) described the importance of administrator commitment to support the integration of technology into the ID of an organization's programs. 


\section{Macrothink}

Though universities have provided eLearning in online asynchronous courses since the late 1900 's, the delivery modality has not advanced significantly since its early development. Gassler et al., wrote, "Learners often get stuck while using today's eLearning systems because they can't motivate themselves to use [new modalities] ... for learning. In contrast, the same learners make use of their computers, their cell phones, and similar tools without such effort" (p. 1). Education and training institutions have been slow to adapt to the needs of the younger generations, or to the methods used routinely in social media and gaming. E-learning pioneer Mark Grensky (as cited in Gassler et al., 2014) wrote that trainers and trainees are "so different in their approach, outlook, style and needs that they can hardly communicate" (p. 2).

\subsection{Scenario-based Learning Approach}

Scenario-based learning (SBL) is an instructional design approach used in formal continuous PD in the workplace. The process of SBL includes a variety of elements. First, the designer identifies the overarching competencies sought and the learning outcomes. Second, she develops scenarios with real-world applications. Clearly defined assessment tasks include rubrics and provide for metacognitive development. Participants demonstrate their learning with work artifacts. Participants share their artifact with peers, then receive and give feedback. The participant-learners write a self-reflection. Finally, the instructor measures/rates the artifact for evidence of growth (Karunanayaka et al., 2018, p. 186). The SBL process compared favorably with Kyprianou and Nikiforou's (2016) informal CPD process, which used online tools to support reflection-in-action. Reflection-on-action supported learners' successful efforts to "create a more efficient working environment ..." (p. 252). Figure 1 provides a model of SBL approach including guiding principles of design strategies for continuing PD (Karunanayaka, Naidu, Rajendra, \& Ariadurai, 2018, p. 185). 


\section{Scenario-based Learning Approach}

Step 1) Preplanning

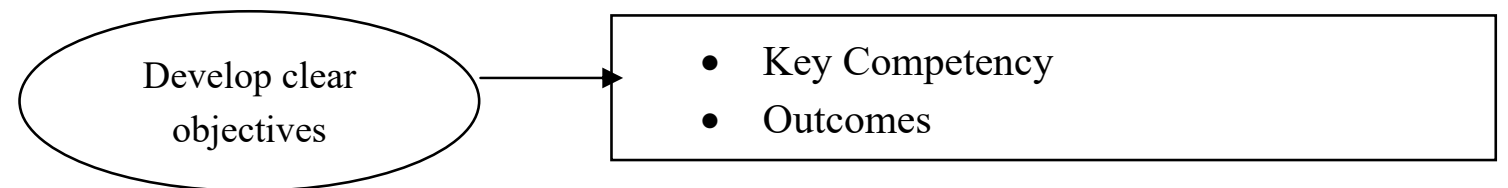

Step 2) Deliver Instructional Content

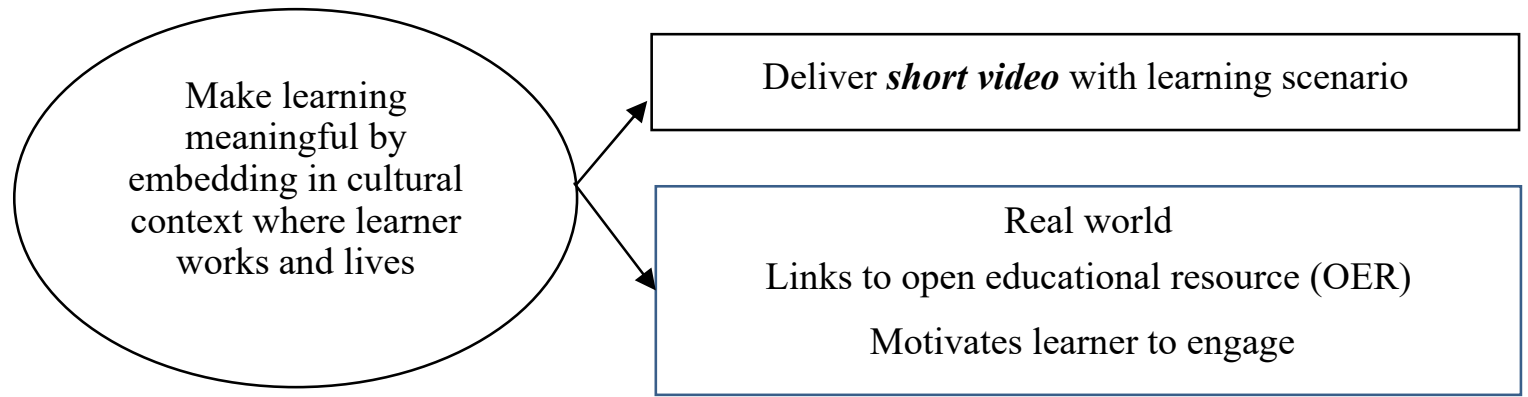

Step 3) Provide Challenge/Assessment Task - Learning Engine Framework

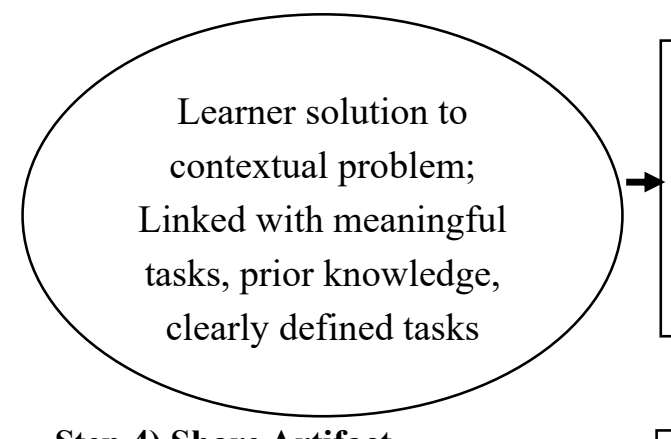

Three types

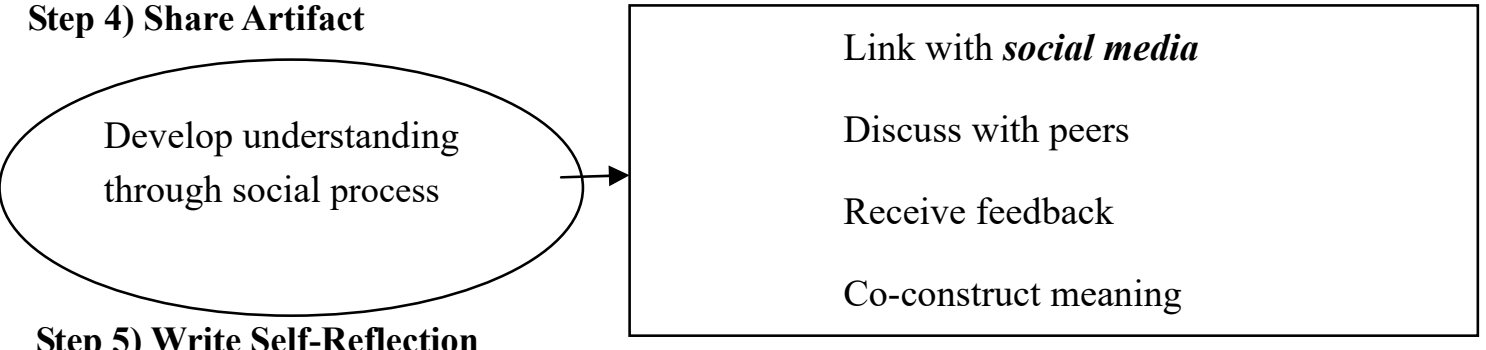

Step 5) Write Self-Reflection

$$
\begin{gathered}
\text { Individual - creative } \\
\text { Group discussion - collaborative } \\
\text { Reflective - self-regulates performance }
\end{gathered}
$$

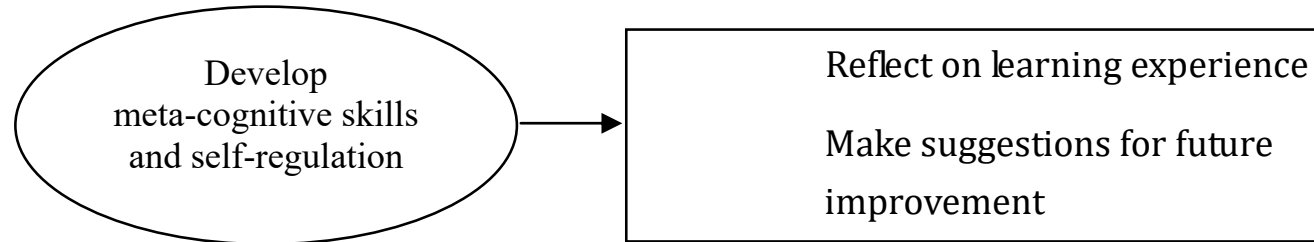

Note: The SBL, approach integrated with IT, requires commitment and support from administration and just-in-time technical support. Refer to Hanshaw and Hanson (2018) for the

Figure 1. Model of scenario-based learning approach with guiding principles of design strategies for continuing PD using open educational resources 


\section{Macrothink}

\section{Methods}

\subsection{Design of the Study}

This was a mixed-methods study testing a new ID using ML and SL to motivate participants to engage in learning. The study received approval through the institution's IRB committee review process. In June 2018, the first author sent a standardized invitation protocol to a convenience and purposeful sample of potential participants experienced at instructional design. An online human subject consent form provided information to participants of the voluntary nature of the study, their rights as human subjects, and the risks and benefits of participation. Participants demonstrated their agreement to participate by clicking a link to begin the study. The primary author collected data during the months of June and July 2018. The data was stored on a secure computer. Personal identifying information was stored separately from the participants' answers and used for follow-up contact to arrange interviews $(N=10)$. The primary researcher followed up via email and scheduled a mutually convenient time for telephone interview. The first author developed the instructional design used in this study from a review of the literature and from his years of experience in the field as an instructional technology developer. The final design included an iterative process of defining training needs of instructional designers on the job. The goal of the training modules was to affect a change in work-place skills or behaviors, evidenced by writing a quality-learning objective.

\subsection{Participants}

The convenience and purposeful sampling of participants were individuals from a variety of backgrounds and technology experience. The local chapter of the Association of Educational Communications and Technology (AECT), located in a large southwestern state of the U.S., requested their members to participate in this study. Additionally, the primary researcher sent email invitations to training instructors and instructional designers, known to the primary researcher, who were working in the aerospace manufacturing industries. The total number of instructional designers in the AECT membership and in the various industries represented by participants in this study would be difficult to determine. Therefore, the statistic of participants as a percentage of the total population was not calculated. Fifty-four respondents responded to the email invitations. Three respondents did not want to be video-recorded using the Flipgrid software. They chose not to move forward with the consent and did not participate in the study. Criteria for participation in this study required individuals be over the age of 18 years and have worked in some capacity as instructional designers. The experience level of the participants ranged from hands-on learning on the job, with no formal education on the topic, to holding graduate degrees in instructional design. Table 1 provides the demographic characteristics of the participants in this study. 


\section{Macrothink}

Table 1. Table of demographic characteristics of participants

\begin{tabular}{lll}
\hline Number of Participants & Education Level & $\begin{array}{l}\text { Years of Experience in Instructional } \\
\text { Design }\end{array}$ \\
\hline 26 & High School & $1-9$ \\
18 & Bachelor's Degree & $0.5-8$ \\
5 & Master's Degree & $3-12$ \\
2 & Doctoral Degree & $12-15$ \\
\hline
\end{tabular}

\subsection{Instruments}

A self-developed, seven-item, Likert-style survey instrument was provided online using the following rating scale: $1=$ strongly disagree; $2=$ disagree; $3=$ neutral; $4=$ agree; $5=$ strongly agree. The aim of the survey was to determine the participants' perceptions of their ML and SL training experience. Survey items captured participants' self-reports of their experience in this particular study. Three categories were used to organize the items by constructs, drawn from a review of the literature on the topic including; personal learning and academic growth, course structure and design, and participants' general experience throughout the study (Hernández, Flórez, Tocora, \& León, 2018, p. 107).

A three-item demographic questionnaire collected participants' years of experience designing or delivering trainings and participant' education level. Researchers used a self-developed, three-item, open-ended, semi-structured interview protocol to collect interview data for developing a rich thick description of participants' perceptions of their training experience. Participants created work samples to demonstrate their learning from their ML and SL online course training modules. These samples provided observable and measurable data to confirm the participants' self-reports of their learning. Researchers used a standardized rubric with four items drawn from Mager's (2001) key elements of learning objectives to evaluate the work samples. Appendices A through $\mathrm{C}$ provide the seven-item online survey instrument, the open-ended interview questions, and the rubric for evaluating the work samples.

\subsection{Procedures}

\subsubsection{Steps of the Process}

This study used the scenario-based learning (SBL) design that included innovative strategies to challenge the participants to engage in the learning, share their learning, and create a work product (Karunanayaka et al., 2018). Initially, the participants observed a simple scenario within a video on how to plant a tree and how to dig a hole. The goal of the interactive ML video module was to develop participants' skills in creating and writing a Mager's (2001) style learning objective including performance, conditions, and criteria. "Flipgrid" provided the video environment and embedded the Likert-style survey so participants could answer the survey questions immediately after participating in the interactive video learning module. Figure 2 provides images of the online demonstration module environment. Figure 3 provides a photo of the "Flipgrid" video environment used by participants to record their responses. 


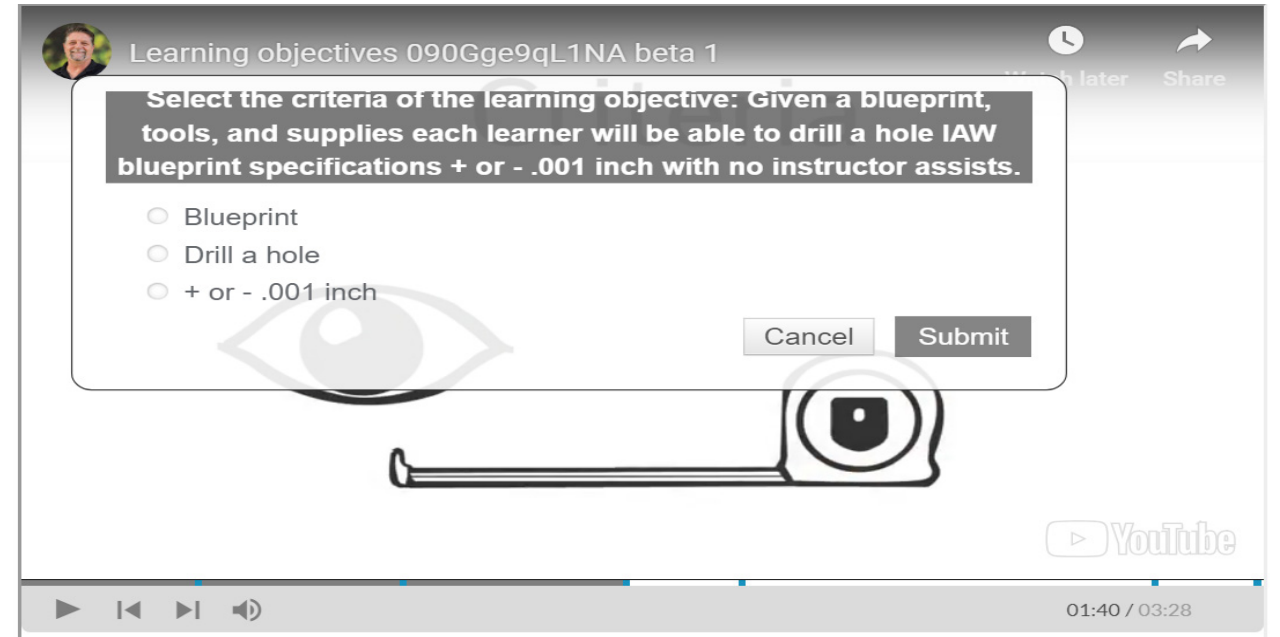

Figure 2. Photos of the online demonstration module environment
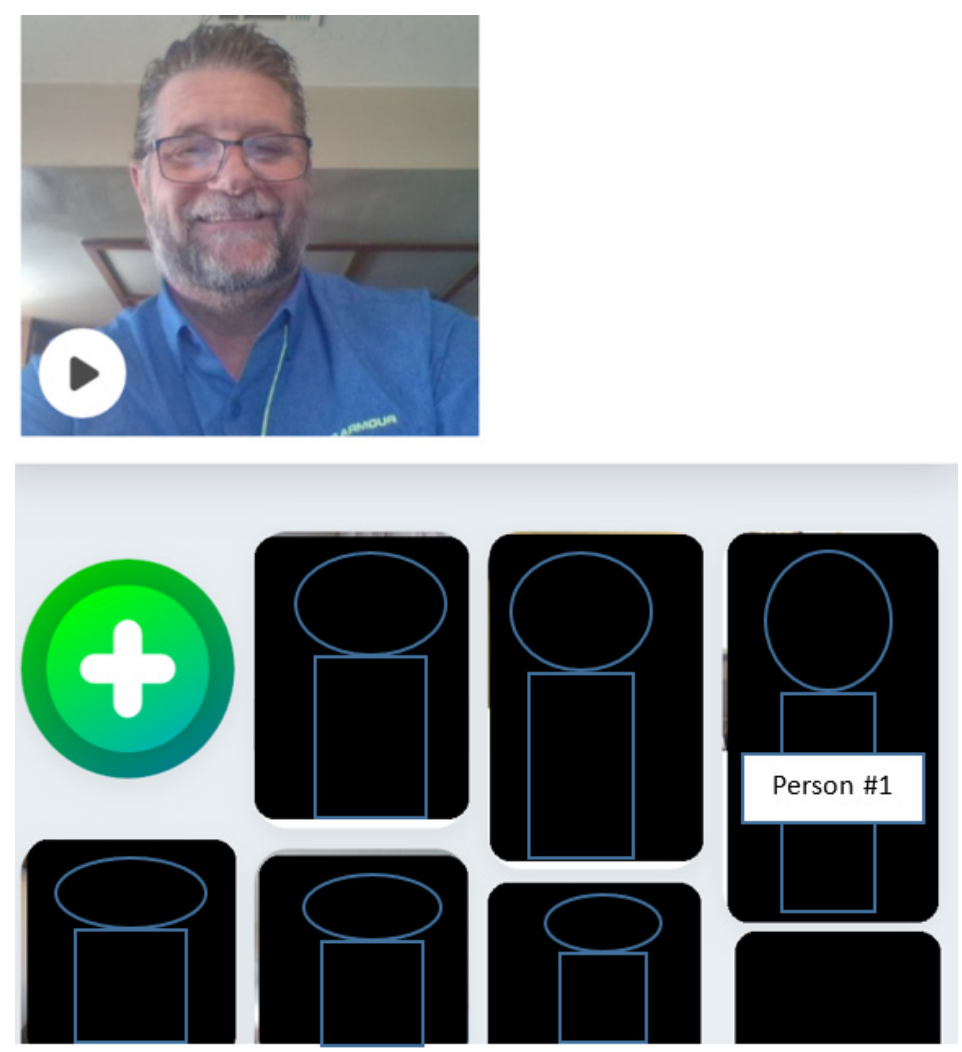

Figure 2. Photo of "Flipgrid" video environment used by participants to record their responses

Within the interactive video, participants responded to three questions; all were about writing learning objectives. While watching a Hapyak video, participants used a link to view an online website with content on Bloom's Taxonomy (Anderson \& Krathwohl, 2001). The participants reviewed the list of measurable action verbs they could use in developing their own learning 
objectives. The video paused while the participants clicked to view the outside resource. Then, participants responded to a prompt to write an enabling learning objective on how to dig a hole and a terminal learning objective on how to plant a tree. The LMS collected participant responses.

The module provided the participant with a "FlipGrid" tool prompting them to respond to an open-ended question such as, "What is the purpose of requiring the basic parts of the learning objective?" Flipgrid software provided ease of use across platforms, including mobile platforms. The participants completed the goal of the module by writing a learning objective according to Mager's elements. Participants also became familiar with the meaning of measurable actions from Bloom's Taxonomy. The next step required the participants to engage in an online SL component. The SL was an asynchronous video discussion. Then, participants reflected on key takeaways and on their experiences writing the Mager's style learning objectives. The participants created their own video reflection (maximum three minutes in length). The participants responded to a minimum of two others' original video posts. At the completion of their responses in the Flipgrid, the participants then worked independently to create a work sample. The work sample included writing of a terminal learning objective on the content of their choosing. After a participant completed the work sample, he or she then completed the seven-item online Liker-style survey.

The researchers used a purposeful approach to design the course to allow the participants to move in a linear fashion throughout the training. The learning management system (LMS) delivered the interactive videos, surveys, collected participants' video responses and work samples. This made the collection of data less complicated than using multiple systems, and easier for the participants to take part in the detailed study by keeping all interactions within one online location. The entire process allowed participants to complete the training and the survey in an online environment with mobile device compatibility. The participants chose their own device for completing the process.

\subsection{Data Analyses Methods}

The surveys, interview data, and work samples were the primary source of insight regarding participants' self-perceptions of the research constructs tested and explored in this study (Yin, 2014). The aim of the study was to determine the participants' perceptions of the online, mobile-device delivery, ML, and SL training experience. The survey data collection quantified participants' ratings of their training experience. The work sample rubric provided a standardized means to rate their ability to develop new skills, or changes in their workplace behaviors, from participating in the ML and SL modules (Mager, 2001).

Quantitative data analyses included correlation analyses and regression of significantly correlated variables. The second author performed a frequency analysis of the participant's self-reports on the survey, item-by-item, to identify trends in the data and to avoid loss of important findings due to the use of group level means. The authors analyzed group-level survey data using a framework of three categories; personal learning and academic growth, course structure and design, and participants' general experience throughout the study (Hernández et al., 2018, p. 107). 
Content analysis of the qualitative data included reading the interview transcripts and open-ended survey responses first to develop a general understanding of the participants' responses and to redact any identifying information provided by the participants. The first author performed a second more thorough reading to identify specific concepts, words, and phrases for coding that reflected the participants' meaning. A third reading provided categories from the codes and emergent themes from those categories. The first author evaluated the participants' coded work samples according to a rubric, rating the work samples on a scale of 1-4 in conformity with Mager's (2001) learning objective exemplars.

\subsubsection{Preset Indices Used for Analyzing the Data}

For this study, acceptable indices for skewness were predetermined to be between \pm 2 and Kurtosis between \pm 7 (Hair, Black, Babin, \& Anderson, 2010; Bryne, 1998). Residuals were reviewed visually for determining normality of the data as well as residuals indices set at less than 20\%, and anti-image correlations > .5 (Fabrigar, Wegener, MacCallum, \& Strahan, 1999; Tabachnick \& Fidell, 2001). Skewed data from self-reports of self-selected research participants is considered normal. Respondent bias is often found in data from self-report surveys due to psycho-social factors (Trochim \& Donnelly, 2006; Field, 2000, 2009; Gravetter \& Wallnau, 2016). According to the literature, issues of normality of the data were not considered relevant when the sample size is sufficiently large ( $>30$ or 40$)$. Assumptions of normality at this level would not preclude the use of parametric procedures (Ghasemi \& Zahediasl, 2012, p. 487).

This study used a scale that operationalized items not intended to represent a unidimensional construct; rather to capture participants' perceptions on individual items related to their experience of the ID of the study. A ratio of seven responses per survey item were collected, sufficient to meet the indices for this study (Tabachnick \& Fidell, 2001). The researchers triangulated the emergent themes found in the data with the literature and the framework developed for the study. The researchers performed a participant check to ensure the conclusions drawn from the study reflected the participants' intentions.

\section{Results}

\subsection{Data Analysis}

The second author performed statistical tests using analytical software, SPSS, Version 23 (IBM, 2015) to determine if the data fit a normal distribution, and was considered acceptable for use with parametric analyses. All but one survey item (Item 4) were negatively left-hand skewed, though considered within normal bounds. Left skew is typical in social science research due to respondent bias of self-report surveys measuring psychosocial constructs. Statistical analyses determined correlations between the items on the survey as a rigorous approach to ensure reliable results from the data (Trochim \& Donnelly, 2006; Field, 2000, 2009; Gravetter \& Wallnau, 2016). Researchers did not connect the participants' demographic data to their survey responses and therefore quantitative analyses were not performed to test for the influences of the demographic factors of the participants on the survey data. 


\subsection{Survey Results}

Table 3 shows the frequency of participants' survey responses by item on the survey. Table 2 shows the correlations between items, means, and standard deviation of each item.

Table 3. Table of frequency of participants' survey responses by item

Likert-type Scale Levels

Survey Item

\begin{tabular}{llllll}
\hline Strongly & & & & Strongly & \\
disagree & Disagree & Neutral & Agree & agree & Total \\
$(1)$ & $(2)$ & $(3)$ & $(4)$ & $(5)$ &
\end{tabular}

Q1 The micro-learning modules made learning seem more relevant to the topic 0 of learning objectives.

$\begin{array}{lllll}0 & 3(5.9 \%) & 13 & 35 & 51 \\ & (25.5 \%) & (68.6 \%) & (100 \%)\end{array}$

Q2 My understanding of the process and requirements to write effective learning objectives increased due to my 0 participation in the micro-learning 0 0 5 $(9.8 \%)$ 46 51 modules.

Q3 My skill level increased due to my participation in the micro-learning 0 modules.

Q4 Participation in the social learning components was important to me.

Q5 I gained new perspectives when watching and listening to what others had 0 to say about their experiences.

0

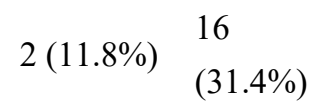

17

$(33.3 \%)$

12

$(23.5 \%)$

51 $(100 \%)$

0

$1(2.0 \%)$

10

$(19.6 \%)$

40

51

$(78.4 \%)$

$(100 \%)$

Q6 It is important for me to gain a broader perspective in order to keep my 0 design skills current.

0

0

$7(13.7 \%)$

44 $(86.3 \%)$

51 $(100 \%)$

Q7 Using a combination of micro-learning and social learning is an effective way to increase my design 0 $2(3.9 \%)$ $7(13.7 \%)$ 42 $(82.4 \%)$ skills. 


\section{Macrothink}

International Journal of Learning and Development

ISSN 2164-4063 2019, Vol. 9, No. 1

Table 2. Correlation matrix of items on the Likert-style survey including $p$ values of significance

\begin{tabular}{|c|c|c|c|c|c|c|c|c|}
\hline Q1 & Q2 & Q3 & Q4 & Q5 & Q6 & Q7 & Mean & $S D$ \\
\hline $\begin{array}{l}\text { Q1The micro-learning modules } 1.00 \\
\text { made learning seem more relevant } \\
\text { to the topic of learning objectives. }\end{array}$ & -.221 & .114 & .081 & .170 & .114 & .255 & 4.62 & 0.63 \\
\hline $\begin{array}{l}\text { Q2 My understanding of the process-. } 221 \\
\text { and requirements to write effective } \\
\text { learning objectives increased due to } \\
\text { my participation in the } \\
\text { micro-learning modules. }\end{array}$ & 1.00 & .021 & -.260 & -.016 & -.132 & -.152 & 4.90 & 0.29 \\
\hline $\begin{array}{l}\text { Q3 My skill level increased due to. } 114 \\
\text { my participation in the } \\
\text { micro-learning modules. }\end{array}$ & .021 & 1.00 & $-.287^{*}$ & -.104 & .204 & -.239 & 4.60 & 0.66 \\
\hline $\begin{array}{l}\text { Q4 Participation in the social.081 } \\
\text { learning components was important } \\
\text { to me. }\end{array}$ & -.260 & $-.287^{*}$ & 1.00 & .033 & .059 & $.383^{* *}$ & 3.68 & 1.09 \\
\hline $\begin{array}{l}\text { Q5 I gained new perspectives when. } 170 \\
\text { watching and listening to what } \\
\text { others had to say about their } \\
\text { experiences. }\end{array}$ & -.016 & -.104 & .033 & 1.00 & .198 & .162 & 4.75 & 0.43 \\
\hline $\begin{array}{l}\text { Q6 It is important for me to gain a. } 114 \\
\text { broader perspective in order to keep } \\
\text { my design skills current. }\end{array}$ & -.132 & .204 & .059 & .198 & 1.00 & -.041 & 4.86 & 0.34 \\
\hline $\begin{array}{l}\text { Q7 Using a combination of. } 255 \\
\text { micro-learning and social learning } \\
\text { is an effective way to increase my } \\
\text { design skills. }\end{array}$ & -.152 & -.239 & $.383^{* *}$ & .162 & -.041 & 1.00 & 4.78 & 0.42 \\
\hline
\end{tabular}

Note. ${ }^{*} p<0.05$ level (2-tailed). ${ }^{*} p<.01$ (2-tailed). Listwise $\mathrm{N}=51_{\mathrm{c}}$.

Item 1 relates to the ability of the ML study design to make the topic more relevant (94\% agreed or strongly agreed).

Item 2 refers to the cognitive component of the ML and revealed $100 \%$ of the respondents agreed or strongly agreed that their understanding of the process and of writing a learning objective improved from the method of ID used in this study.

Item 3 refers to the design of the ML modules to produce a change in workplace behaviors/skills of the participants (96\% of participants agreed or strongly agreed).

Item 4 refers to the participants' appreciation for the SL component in the study design. Thirty-one percent of participants reported they were neutral on the benefit of participation in the SL component as important to them; $2 \%$ disagreed it was important; and 57\% agreed or 


\section{Macrothink}

strongly agreed the SL was important to them.

Item 5 asked participants about their experience with the SL component of the ID, which could be described as an e-mentoring design. Participants learned from others' sharing of their experience and workplace skills. Ninety-eight percent of participants agreed, or strongly agreed, they had gained new perspectives when watching and listening to what others had to say about their learning in the modules.

Item 6 measured the personal value of openness to change and to learn new things that participants' brought with them to the study. All of the participants agreed, or strongly agreed, it was important to them to gain a broader perspective in order to keep their design skills current.

Item 7 captured participants' responses to the overarching question of this study. Approximately $96 \%$ of participants agreed or strongly agreed that the combination of $M L$ and SL was an effective way to increase their design skills.

The researcher performed both a Pearson and Spearman correlation analyses evidencing similar results. Results of Spearman two-tailed bivariate correlation analysis showed Item 4, "Participation in the social learning components was important to me" as significantly correlated with two other survey items; Item 3, "My skill level increased due to my participation in micro-learning modules" ( $p=.043)$, and Item 7, "Using a combination of micro-learning and social learning is an effective way to increase my design skills" $(p=.005)$. Items 3 demonstrated a negative correlation with both Items 7 and 4 .

\subsection{Regression of Correlated Items on DV}

Items 3 and 4 were entered simultaneously into a linear regression analysis with Item 7 as the $\mathrm{DV}$, reflecting the overarching question of this study, "Using a combination of micro-learning and social learning is an effective way to increase my design skills." A significant relationship existed between the IV, Item 4, explaining a significant change in the DV $\left(\mathrm{R}^{2}=.171\right)$, and demonstrating a small effect $\left(F_{(2,48)}=4.966, p=.012\right)$. Table 4 shows the results of the regression analysis using Items 3,4 , and 7 . Section 5 provides a discussion of the implications of this relationship. 


\section{Macrothink}

Table 4. Regression results of all items on Item 7 including $\beta$ and $p$ values.

\begin{tabular}{lcc}
\hline \multicolumn{1}{c}{$\beta$} & $p$ & $N$ \\
\hline Q7 Using a combination of micro-learning & & 51 \\
and social learning is an effective way to \\
increase my design skills. \\
Q3 My skill level increased due to my -.138 \\
participation in the micro-learning \\
modules. \\
$\begin{array}{l}\text { Q4 Participation in the social learning } .356^{*} \\
\text { components was important to me. }\end{array}$
\end{tabular}

Note: ${ }^{*} \mathrm{p}<.05, R^{2}=.171, F_{(2,48)}=4.966$.

\subsection{Interview - Emergent Themes}

The researchers evaluated participants' $(N=10)$ responses to the self-developed open-ended interview protocol delivered via telephone. Analyses included a brief reading of the transcription data for familiarity with the content, a deeper reading to identify and create codes, and a third reading to identify categories and emergent themes. Three themes emerged from the analyses: participants' reported the instructional design met their primary goal for the PD (to learn something they could immediately use on the job), they gained additional job related perspectives, and felt the instructional design enabled them to expand the scope of skills in their craft. Table 5 shows the emergent themes and supporting participant responses. 
Table 5. Interview questions and emergent themes

\begin{tabular}{|c|c|}
\hline Emergent Themes & Participant Quotes \\
\hline $\begin{array}{l}\# 1 \text { - The primary goal for PD was } \\
\text { to learn something they could use } \\
\text { immediately on the job. }\end{array}$ & $\begin{array}{l}\text { "I am currently working on a project where we are writing objectives. I was } \\
\text { able to take what I learned and make some changes to what we wrote." }\end{array}$ \\
\hline $\begin{array}{l}\text { Application: ML has specific and } \\
\text { focused content that resulted in } \\
\text { ease of use for immediate } \\
\text { application to specific job needs. }\end{array}$ & $\begin{array}{l}\text { "The use of the microlearning and social learning aspects gave me a greater } \\
\text { opportunity to apply what I was immediately learning..." } \\
\text { "[I liked] ... the simplicity and focus of the microlearning" }\end{array}$ \\
\hline $\begin{array}{l}\# 2 \text { - Participants sought to gain } \\
\text { additional job related perspectives. } \\
\text { Application: SL is inclusive of a } \\
\text { variety of perspectives and } \\
\text { therefore allows individual growth } \\
\text { opportunity. }\end{array}$ & $\begin{array}{l}\text { "I initially thought there may be really one way to see how objectives could be } \\
\text { applied. After viewing other peoples thoughts I saw a bigger picture" } \\
\text { "...seeing the other people in the grid made the learning more personal." }\end{array}$ \\
\hline $\begin{array}{l}\# 3 \text { - Participants' sought to expand } \\
\text { the scope of skills in their craft } \\
\text { beyond other designers. }\end{array}$ & $\begin{array}{l}\text { "The best part about this is that I was able to explain performance objectives } \\
\text { clearly to my team." }\end{array}$ \\
\hline $\begin{array}{l}\text { Application: ML and SL provided } \\
\text { greater opportunity for success } \\
\text { because of multiple pathways for } \\
\text { learning. }\end{array}$ & $\begin{array}{l}\text { "I wanted to bring something different to my team. I think the microlearning } \\
\text { can help me do this on an ongoing basis." }\end{array}$ \\
\hline
\end{tabular}

\subsection{Work Samples}

This study looked at gaining and growing skills from the perspective of PD. Participants had varying ideas, and differing degrees of ability using the concept of writing Mager's (2001) style learning objectives. Writing a learning objective was in the realm of the participants' current level of learning in their profession. Participants created formative work samples with content support during the training portion of the video. The participants also created a terminal work sample after the tutorial without support. The work samples created within the interactive video showed a high level of quality. Terminal work samples produced forty-seven of 51 participants (94\%) able to write learning objectives in accordance with the rubric. Four work samples did not pass the rubric requirements because the participants did not use measurable verbs in their objectives. For example, two of the terminal objectives written by participants used the word "know" as the performance action, and two others used the verb "understand." Both these objectives failed the "measurable objective" word requirement of the Mager's (2001) key elements of learning objectives rubric used to evaluate the samples. The words "know" and "understand" were neither in Bloom's Taxonomy provided in the training module. 


\section{Ml Macrothink}

The experience level of the four participants that provided unsatisfactory work samples averaged 5.2 years (four, four, seven, and six) in the field of instructional design. The average years of experience for the overall study was 3.6 years. Therefore, a greater number of years of experience working in the field skill not guarantee a passing level in creating a measurable learning objective in the work sample.

\subsection{Summary of the Findings}

The analyses of the data included quantitative analyses of the survey data including correlation analyses of the survey items, regression of significantly correlated items on Item 7 (DV), analysis of work samples to validate participants' self-reports, and review of qualitative data for emergent themes of participants' perceptions of their experience in the study.

Regression analysis revealed participants' valuation of the SL component of the ID explained variations in participants' views that the ML and SL instructional design of this study was effective. The result suggests that as participants' have opportunities to share their learning with others, making it "more personal" and providing a "bigger picture" or broader perspective on the learning, the participants' motivation to engage the instruction increased and skills improved. The qualitative emergent themes supported this finding, Theme \#3, "Participants sought to gain additional job related perspectives." Participants also sought to learn something they could use immediately and to expand the scope of their skills competitively. Participants reported the ID of this study met their goals for PD. Contrary findings included the participants self-reporting positive experiences with the ML component in the qualitative data and a negative correlation of ML with the outcome variable in the quantitative analysis of the survey data.

\subsection{Testing the Hypotheses}

Though participants reported the effectiveness of the combination of ML and SL for the development of professional skills, Item 7 (DV) had no significant correlation with Items 1, 2, 5, and 6. Item 7 did have a significant though negative correlation with Item 3, "My skill level increased due to my participation in the micro-learning modules," and a significant positive correlation with Item 4, "Participation in the social learning components was important to me." Therefore, the results warranted not rejecting the null hypothesis for Items 1, 2, 3, 5 and 6 and rejecting $\mathrm{H}_{0}$ in favor of $\mathrm{H}_{\mathrm{A}}$ for Item 4 .

Hypothesis $_{01}$ - There is no relationship between the participants' perceptions that using a combination of ML and SL is an effective way to increase their design skills (Item 7) and individual mean scores calculated from the items on the Likert-style study survey.

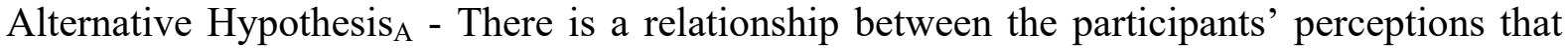
using a combination of ML and SL is an effective way to increase their design skills (Item 7) and individual mean scores calculated from the items on the Likert-style study survey.

Analysis of the participants' work samples revealed evidence in support of participants' self-reports that their skills improved as a result of participating in the ML and SL modules of the study' ID. Therefore, findings provided evidence to reject $\mathrm{H}_{02}$ in favor of $\mathrm{H}_{\mathrm{A}}$. 
Hypothesis $_{02}$ - There is no relationship between participants' self-reports of their belief ML and SL improved their skills in instructional design and their work sample quality.

Alternative Hypothesis - There is a relationship between participants' self-reports of their belief ML and SL improved their skills in instructional design and their work sample quality.

\section{Discussion}

In a prior study, professionals reported a readiness for using ML and SL modalities in the workplace for PD. The participants in this study reported that the ML and SL combination was effective to improve their skills, consistent with the previous study findings (Hanshaw \& Hanson, 2018). Evaluation of participants' work samples, produced during their training, e.g. at writing learning objectives for instructional design on the job, also confirmed participants' self-reports. However, online SL component of the modules was the only operationalized item demonstrating positive significance in explaining the participants' perceptions of the effectiveness of the study design. Participants' responses on the survey Item 6, "It is important for me to gain a broader perspective in order to keep my design skills current," indicated a high level of openness to change and to learn new ideas. The literature refers to this concept as "innovativeness." The qualitative emergent Theme \#2 supported this quantitative finding and compared favorably with Park, Kim, Shon, and Shim's (2013) study, which measured innovativeness using nine statements, for example, "I am interested in new ideas or information," "I am interested in news that deals with new development in technologies or discovery,' etc. (p. 1766). Participants' interview responses also revealed that gaining new perspective (from others' thoughts and contributions) was a priority for them in their PD. The findings aligned with Hernández et al., (2018) key elements of evaluating instructional design including personal learning and skill development, course structure and design, and participants' perceptions and experiences throughout the study p. 107).

\subsection{Contrary Findings}

In this study, a correlation and regression analysis revealed Item 6 did not directly explain changes in participants' perceptions of the value of ML and SL to learn new workplace skills. A review of the literature provided an explanation for this apparent discrepancy. Uslu (2018) reported the quality of learner openness had a mediating influence rather than a direct influence on the DV through the learner's attitude toward technology integration.

Four of the 51 participants used verbs that were not on Bloom's Taxonomy once the resource was no longer available to them online, suggesting a lack of independence in their learning. For these participants, their years of experience did not predict sample quality. This result speaks to the need for ongoing PD within the field of instructional design as well as all fields of practice.

\subsection{Conclusion}

This study explored the perceptions of 51 participants who were either classroom trainers or instructional designers in their jobs. After participating in the research-based design modules delivered online using a combination of ML and SL, the respondents reported that this method 
was a viable way to develop practical skills immediately applicable in the workplace. This study provided research-based evidence of the potential for ID that provides engaging learning experiences using a combination of ML and SL on mobile devices. The instructional design provided in this study has the potential to match the needs of the current generation of workplace learners and instructional designers/trainers for use in continuous PD.

SL replicates the e-mentoring process discussed in the literature. E-mentoring provides real world, just-in-time support, of the experiences and knowledge from one person to another to improve their personal and workplace skills. Universities and formal institutions have not kept up with the needs of the current group of learners. Administrators can develop new professional development trainings integrating informal process not widely used in the formal structures of institutions.

Results revealed participants reported value in the ML and SL components of the study's ID. Combining the tools of ML and SL allows instructional designers to build meaningful learning experiences that engage learners in ways they report as useful. The participants in this study reported they were prepared and interested in learning from others and in sharing their experiences and knowledge using social media and Internet tools. They wanted practical tools immediately applicable in the workplace. Technology gives us the rich tools we need to provide this learning using asynchronous and synchronous video software to engage learners through informal learning opportunities. This study further demonstrated that SL served participants' needs to learn differently than their current PD often delivered face-to-face on the job in brick-and-mortar buildings. With the rapid advancement of technologies and information systems, providing up-to-date resources to meet the needs of adult learners can mean the difference between success and failure on the job.

Further study is necessary to explain the negative correlation of the ML component with the study DV - effectiveness of the ML and SL design. In the face of the more powerful variable of SL, ML may lose some of its effectiveness.

\subsection{Limitations}

This study was limited to participants in the role of trainers and instructional designers selected by convenience and purposeful sampling. The results may not generalize to other populations. Due to limitations of time, this was not a longitudinal study. However, this study expanded on a previous study performed by the authors (Hanshaw \& Hanson, 2018). Researchers were aware of the tendency toward social desirability responses in studies where participants self-select as volunteers in the research. Researchers used rigorous design protocols to protect against negative effects of the researchers' bias including triangulating the findings with the review of the literature. The sample size of 51 participants was reasonable for performing the quantitative analyses, though a larger sample would provide increased reliability for developing valid conclusions that might generalize to other populations.

\subsection{Implications}

It is important to reflect on the findings of this study in preparation for needed reforms in the current design of workplace continuous PD. Institutions must begin to develop policies and 
structures that support formal changes in pedagogical delivery that reflect the informal learning engaged in by their employees or students. Effective and ethical ID requires recognizing the needs and context of the new generation of learners coming into the workplace. The new internet-based technologies individuals are currently using successfully can be an informal resource for designing formal learning opportunities.

ML and SL can have multiple benefits for learning and developing professional skills. The methods tested in this study leveraged the preexisting skill-sets of adult learners to help employees grow professionally. ML and SL processes embedded in classes and or PD trainings is a viable alternative to current designs. For example, the methods described in this study are useful for annual certification or recertification coursework in a variety of fields.

Adult learners typically have a broad range of experiences. ML and SL can leverage these abilities and skills by recognizing its association with e-Mentoring. SL, as described in this study, can be a part of the motivating factor that engages long-term employees to share their knowledge with newer employees, or students, to lift each other's learning. This finding suggests that ML and SL are a way to capture and effectively distribute institutional knowledge into the organization, creating intellectual capital.

The number of years of experience did not guarantee a passing level of participants' work samples. Therefore, it is important to implement PD on a continuous basis. The main characteristics of the ML and SL are flexible delivery, speedy development process, and meaningful input opportunities for participants, including content creation, through the SL component.

\subsection{Recommendations for Future Research}

Learning and development professionals and researchers can grow the knowledge base for ML and SL. Future research could include performing observations and interviews to develop a rich, thick understanding of the participants' experiences over a longer period of time using the ID provided in this study. Researchers could perform follow-up observations on the job, by going back to the context to see if the results were persistent over time. A replication of this study would determine if the findings of this study are repeatable. A new study could include collecting a work sample prior to beginning the study for use as a baseline to compare with the post-training work sample. A next step would be to use the ID provided here to build skills that are outside of the participant's current profession or skill set. An important next research step would be to design a study that explores the negative correlations between ML in the presence of SL and the influence on participants' perceptions of the effectiveness of this ID for use in PD.

\section{References}

Anderson, L. W., \& Krathwohl, D. R. (2001). A taxonomy for learning, teaching, and assessing (Abridged Edition). Boston, MA: Allyn and Bacon.

Billings, E. M. H., \& Kasmer, L. (2015). Micro-cycle teaching experiments as a vehicle for professional development. Mathematics Teacher Education and Development, 17(2), 165-181. 
Retrieved January 31, 2019 from https://files.eric.ed.gov/fulltext/EJ1085905.pdf

Bruck, P. A., Motiwalla, L., \& Foerster, F. (2012, June). Mobile learning with micro- content: A framework and evaluation. In Bled eConference (p. 527-543). https://domino.fov.unimb.si/proceedings.nsf/0/c3fb705e43f2f302c1257a2a0032cc30/\$FILE/P38_Bruck_35.pdf

Byrne, B. M. (1998). Structural equation modeling with Lisrel, Prelis and Simplis: Basic concepts, applications and programming. Mahwah, NJ: Erlbaum.

Chen, B., \& Bryer, T. (2012). Investigating instructional strategies for using social media in formal and informal learning. The International Review of Research in Open and Distributed Learning, 13(1), 87-104. https://doi.org/10.19173/irrodl.v13i1.1027

Cochrane, T. D. (2014). Critical success factors for transforming pedagogy with mobile Web 2.0. British Journal of Educational Technology, 45(1), 65-82. https://doi.org/10.1111/j.1467-8535.2012.01384.x

Dewey, J. (1910). How we think. Boston: D. C. Heath \& Co.; selections from Part One, "The Problem of Training Thought." Retrieved January 31, 2019 from http://rci.rutgers.edu/ tripmcc/phil/dewey-hwt-pt1-selections.pdf

Dewey, J. (1933). How we think: A critical restatement of the relation of reflective thinking to the educative process. Boston: D. C. Heath.

Fabrigar, L. R., Wegener, D. T., MacCallum, R. C., \& Strahan, E. J. (1999). Evaluating the use of exploratory factor analysis in psychological research. Psychological Methods, 4(3), 272-299. http://dx.doi.org/10.1037/1082-989X.4.3.272

Field, A. (2000). Discovering statistics using SPSS for windows. London-Thousand Oaks-New Delhi: Sage publications.

Field, A. (2009). Discovering statistics using SPSS. London: SAGE.

Gassler, G., Hug T., \& Glahn C. (2014). Integrated micro-learning - An outline of the basic method and first results. International Conference on Interactive Computer Aided Learning (ICL).

Gedik, N. (2017). Examining the conceptualization of instructional technology in Turkey. Contemporary Educational Technology, 8(1), 76-98. Retrieved from https://eric.ed.gov/?id=EJ1126836

Ghasemi, A., \& Zahedias1, S. (2012). Normality tests for statistical analysis: A guide for non-statisticians. International Journal of Endocrinology Metabolism, 10, 486-489. https://doi.org/10.5812/ijem.3505

Giurgiu, L. (2017). Microlearning an evolving elearning trend. Scientific Bulletin, 43(1), 18-23. https://doi.org/10.1515/bsaft-2017-0003

Gravetter, F., \& Wallnau, L. (2014). Essentials of statistics for the behavioral sciences $\left(8^{\text {th }}\right.$ ed.). Belmont, CA: Wadsworth. 
Hair, J. F., Black, W. C., Babin, B. J., \& Anderson, R. E. (2010). Multivariate data analysis. Englewood Cliffs, NJ: Prentice Hall.

Hanshaw, G. \& Hanson, J. (2018) A mixed methods study of leaders' perceptions of microlearning for professional development on the job. International Journal of Learning and Development, 8(3), 1-21. https://doi.org/10.1108/14691931111181742

Hattie, J. (August 2, 1999). Influences on student learning. Inaugural Lecture: Professor of Education, University of Auckland. Retrieved July 12, 2016 from http://projectlearning.org/blog/wp-content/uploads/2014/02/Influeneaces-on-Student-Learnin g-John-Hattie.pdf

Hattie, J. (2012). Visible learning for teachers: Maximizing impact on learning. New York: NY, Routledge.

Hernández, C. H., Flórez, F. B., Tocora, M. A., \& León, D. G. (2018). Problem based learning and the development of professional competences: An experience in the field of biomedical engineering. TOJET: The Turkish Online Journal of Educational Technology, 17(3), 104-112. https://files.eric.ed.gov/fulltext/EJ1184212.pdf

Jaokar, A. (2007). Mobile Web 2.0, Microlearning, Intertwingularity, and Mobile widgets. Educational Technology, 47(6), 43-45. Retrieved from http://www.jstor.org/stable/44429529

Karunanayaka, S. P., Naidu, S., Rajendra, J. C. N., \& Ariadurai, S. A. (2018). Designing continuing professional development MOOCs to promote the adoption of OER. Open Praxis, 10(2), 179-190. https://doi.org/10.5944/openpraxis.10.2.826

Knowles, M. (1984). Andragogy in action. San Francisco: Jossey-Bass.

Kovalchuck, V. \& Vorotnykova, I. (2017). E-coaching, E-mentoring for lifelong professional development of teachers within the system of post-graduate pedagogical education. Turkish Online Journal of Distance Education, 18(3), 1302-6488. Retrieved from https://files.eric.ed.gov/fulltext/EJ1147624.pdf

Kyprianou, M., \& Nikiforou, E. (2016). Teacher professional learning: Developing with the aid of technology. Research-publishing.net, Paper presented at the EUROCALL 2016 Conference (23rd, Limassol, Cyprus, Aug 24-27, 2016). Retrieved from https://files.eric.ed.gov/fulltext/ED572187.pdf

Lamb, L. C., DiFiori, M. M., Jayaraman, V., Shames, B. D., \& Feeney, J. M. (2017). Gamified Twitter microblogging to support resident preparation for the American Board of Surgery in-service training examination. Journal of Surgical Education, 74(6), 986-991. https://doi.org/10.1016/j.jsurg.2017.05.010

Lindsay, H. (2016). More than 'continuing professional development': A proposed new learning framework for professional accountants. Accounting Education, 25(1), 1-13. https://doi.org/10.1080/09639284.2015.1104641

Mager, R. F. (2004). Preparing instructional objectives. Mumbai: Jaico Pub. House. 
Matzen, N., \& Edmunds, J. (2007). Technology as a catalyst for change. Journal of Research on Technology in Education, 39(4), 417-430. https://doi.org/10.1080/15391523.2007.10782490

Maxwell, J. (2013). Qualitative research design: An interactive approach. Thousand Oaks, CA; Sage Publications.

Musa, T. S. (2014). The evaluation of micro teaching method used in the training of primary school teachers in Turkey. Educational Research and Reviews, 9(23), 1315-1322. https://doi.org/10.5897/ERR2014.1910

Park, N., Kim Y., Shon, H. Y., \& Shim, H. Y. (2013). Factors influencing smartphone use and dependency in South Korea. Computers in Human Behavior, 29, 1763-1770. https://doi.org/10.1016/j.chb.2013.02.008

Sarac, H. (2018). Use of instructional technologies by teachers in the educational process: Metaphor analysis study. European Journal of Educational Research, 7(2), 189-202. https://doi.org/10.12973/eu-jer.7.2.189

Schoology (2018). Schoology. Retrieved from https://www.schoology.com/

Siadaty, M., Gašević, D., \& Hatala, M. (2016). Measuring the impact of technological scaffolding interventions on micro-level processes of self-regulated workplace learning. Computers in Human Behavior, 59,469-482. https://doi.org/10.1016/j.chb.2016.02.025

Stokely, T. (December 21, 2015.). What we heard: The three big buzzwords and phrases of 2015. ENerd Tracey's blog: eLearning thoughts and ponderings. Retrieved July 12, 2016 from

https://enerdtracey.wordpress.com/2015/12/21/what-we-heard-the-three-big-buzzwords-and-p hrases-of-2015/

Tabachnick, B. G., \& Fidell, L. S. (2001). Using Multivariate Statistics. Boston: Allyn and

Bacon.

Taylor, D. C., \& Hamdy, H. (2013). Adult learning theories: Implications for learning and teaching in medical education: AMEE Guide No. 83. Medical Teacher, 35(11), e1561-e1572. https://doi.org/10.3109/0142159X.2013.828153

Trochim, W. M., \& Donnelly, J. P. (2006). The research methods knowledge base $\left(3^{\text {rd }} \mathrm{ed}\right)$. Cincinnati, OH: Atomic Dog.

Uslu, Ö. (2018). Factors associated with technology integration to improve instructional abilities: A path model. Australian Journal of Teacher Education, 43(4), 30-50. https://doi.org/10.14221/ajte.2018v43n4.3

Waack, S. (2015). Hattie ranking: 195 influences and effect sizes related to student achievement. Visiblelearning.org. Retrieved July 12, 2016 from http://visible-learning.org/hattie-ranking-influences-effect-sizes-learning-achievement/ 


\section{Macrothink}

International Journal of Learning and Development

ISSN 2164-4063 2019, Vol. 9, No. 1

Wen, C., \& Zhang, J. (2015). Design of a microlecture mobile learning system based on smartphone and web platforms. IEEE Transactions on Education, 58(3), 203-207. https://doi.org/10.1109/TE.2014.2363627

Yin, R. (2014). Case study research: Design and methods. Thousand Oaks, CA; Sage Publications.

\section{Appendix A}

Survey Questions

Participants took the survey online through Survey Gizmo.

\section{Survey Title: Micro-learning and Social Learning for Skill Development}

Rate the following statements on a scale from 1 - 5

$1=$ never

$2=$ occasionally

$3=$ frequently

$4=$ almost always

$5=$ always

1. The micro-learning modules made learning seem more relevant to the topic of learning objectives.

2. My understanding of the process and requirements to write effective learning objectives increased due to my participation in the micro-learning modules.

3. My skill level increased due to my participation in the micro-learning modules.

4. Participation in the social learning components was important to me.

5. I gained new perspectives when watching and listening to what others had to say about their experiences.

6. It is important for me to gain a broader perspective in order to keep my design skills current.

7. Using a combination of micro-learning and social learning is an effective way to increase my design skills. 


\section{Appendix B}

Interview Protocol

\begin{tabular}{|l|l|}
\hline Question & Interview Questions \\
\hline 1 & $\begin{array}{l}\text { After participating in the learning module, were you able to, immediately, apply } \\
\text { what you learned? }\end{array}$ \\
\hline 2 & $\begin{array}{l}\text { How did viewing other participants comments on the Flipgrid help you to } \\
\text { understand the content better, or give you more insight? }\end{array}$ \\
\hline 3 & $\begin{array}{l}\text { From your perspective, what is the primary reason the microlearning and social } \\
\text { learning approach to development effective, or not effective? }\end{array}$ \\
\hline
\end{tabular}

\section{Appendix C}

Rubric for objectively measuring work samples quality

\begin{tabular}{|l|l|l|l|l|}
\hline 1 & 2 & 3 & 4 & Total \\
\hline $\begin{array}{l}\text { Condition: The } \\
\text { conditions under } \\
\text { which the students will } \\
\text { perform the behavior } \\
\text { in the objective are } \\
\text { clear and well defined }\end{array}$ & $\begin{array}{l}\text { Performance } \\
\text { objective } \\
\text { contains a a } \\
\text { measurable } \\
\text { behavior. }\end{array}$ & $\begin{array}{l}\text { Criteria: The } \\
\text { criteria for } \\
\text { successfully } \\
\text { completing the } \\
\text { objective is clear } \\
\text { and pertains to the } \\
\text { subject matter. }\end{array}$ & $\begin{array}{l}\text { Correlates: } \\
\text { objective correarly } \\
\text { content topic for the } \\
\text { which they chose to } \\
\text { write the objective. }\end{array}$ & \\
\hline
\end{tabular}

\section{Copyright Disclaimer}

Copyright for this article is retained by the author(s), with first publication rights granted to the journal.

This is an open-access article distributed under the terms and conditions of the Creative Commons Attribution license (http://creativecommons.org/licenses/by/4.0/). 